\title{
Fidelity Behaviour of Very Small Craft Enterprises Customers ADANKANHOUNDE Thierry Mahougnon*
}

National University of Sciences, Technologies, Engineering and Mathematics (UNSTIM), Abomey, Benin

\begin{abstract}
There are several references available on the concept of loyalty, its various forms and advantages to enable companies to secure a stable customer base. After a typology of the various major forms of loyalty based on consumer behavior towards products or brands, this paper attempts to identify the various forms of loyalty adopted by the customers of artisanal small businesses. Its main contribution is the correlation established between the various forms of loyalty that can be adopted by the Very Small Enterprises (VSE) customers. The quantitative methodological approach adopted is based on a structured attitudinal questionnaire administered to nearly 419 small businesses. The results show that Very Small Enterprises do not adopt normative fidelity. A correlation emerged between the behavioral fidelity and the attitudinal and affective fidelity developed by the same customers.
\end{abstract}

Keywords: Customers; Small craft; Type of fidelity

\section{Introduction}

Now days, no company can out pass marketing whatever its size and activities. Indeed, the development of a company depends not only on the satisfaction its goods and/or services provide to customers but also on the relationship it has with the latter. As a result, the loyalty of the clientele becomes a focus and the basis of several researches. But according to Pacitto and Julien [1], the interest shown in recent years to entrepreneurship is often confused with company creation of did not make it possible to advance in the knowledge of the marketing applied to the very small enterprises (VSEs). To this problem, they add that "the somewhat confusing character of the management of these enterprises which does not favor the multiplication of studies".

Since VSEs are mainly business-based companies, they produce mostly customer services in a highly competitive and varied environment. It is therefore advisable to explore the loyalty behaviors of the clients of these companies in order to enable them to develop strong and appropriate loyalty tools. Customers and their loyalty, despite their rarity and demands, have become a key factor in guarding against difficulties and ensuring prosperity in the challenging trade environment. To this end, the mastery of the types of loyalty adopted and the link that exists between these different types of loyalty will allow the VSE to know the tools on which it must rely to make the customer loyal and benefit from the inherent advantages.

This article aims to explore the different types of loyalty in very small craft businesses and the relationship that might exist between them. To achieve this, it is divided into three parts: the first deals with the concept of fidelity and the VSE while the second is devoted to the methodology adopted to collect and analyze the results. In the third part, the various results obtained are presented.

\section{Concept of fidelity and small craft of service}

In this section, the notions of loyalty as well as of small craft of service have been clarified through the available literature.

Definition of fidelity: Researchers have been interested in loyalty for many years. But recent interest in business can be explained by two main reasons: consumer instability [2] and the high cost of conquering new customers. Since a stable base of loyal customers ensures constant sales volumes and profits [3], the loyal customer becomes a prescriber of the product and recommends it to his entourage through a wordof-mouth effect [4]. Therefore, when a company establishes a stable base of loyal clientele, Trinquecoste [5] informs that this creates for it a "perfectly legal monopoly". What is then the definition of fidelity?

According to Olivier [6], customer loyalty can be defined as "a deep commitment to regularly buy a product or service more appreciated than others, in spite of changing circumstances or marketing actions with a potential impact sufficient to train a change in behavior". From this definition, it appears that in order to qualify a client as loyal, one must observe a repetitive behavior of purchase of the same brand or the same product: this is termed behavioral fidelity. However, it may happen that the brand or product may be the only one referenced over a long period. The customer therefore has no choice but to buy it regularly. Also, when the customer is already satisfied with the brand, he may try to buy it regularly "with the view of facilitating and simplifying life or behaving in a coherent way vis-à-vis what he already knows, thinks and believes" [7]. Considering repeat purchases as the only measure of brand loyalty, word-of-mouth effect does not appear. It is for this reason that, according to Jacoby and Kyner [8], "the simple observation of purchasing acts does not allow to correctly understanding the notion of fidelity". These scholars further indicate that "for a consumer to be truly loyal, he must not only buy the mark repeatedly but also develop positive attitudes towards it. The loyal consumer thus appreciates the brand he buys and develops an emotional connection with it. And, for this sole reason, he keeps buying it and accordingly is loyal to it".

This new attitudinal and affective implication of the definition seems to be more accurate insofar as the attitudinal dimension refers to true fidelity, which is manifested by an affective link that leads the consumer to maintain a lasting behavior favorable to the brand in spite of critical incidents that may punctuate the commercial relationship [4]. But these different authors tend to make attitudinal fidelity complementary to behavioral fidelity. Due to migratory considerations and the development of information and communication techniques,

*Corresponding author: ADANKANHOUNDE Thierry Mahougnon, Vocational and Technical Teacher, Training School of Lokossa, Benin, Tel: +00229 66016980 E-mail: desboiset@yahoo.fr

Received July 26, 2017; Accepted August 03, 2017; Published August 10, 2017

Citation: Mahougnon AT (2017) Fidelity Behaviour of Very Small Craft Enterprises Customers. J Account Mark 6: 248. doi: 10.4172/2168-9601.1000248

Copyright: @ 2017 Mahougnon AT. This is an open-access article distributed under the terms of the Creative Commons Attribution License, which permits unrestricted use, distribution, and reproduction in any medium, provided the original author and source are credited. 
a client may, because of the distance, cease to adopt behavioral fidelity but continue to have a feeling of affection and a favorable attitude towards the brand, the product or the company. Positive word-ofmouth effect can be developed while repeated shopping behavior stops. This is attitudinal and affective fidelity.

Referring to the conclusions of Allen and Meyer [9], there is another form of fidelity called normative fidelity. It reflects the internalization of values, codes, norms that have been inculcated by Consumer culture, family or community of reference. The client tends to develop this form of fidelity through followership or constraint, i.e., respecting the norms of the environment in which he operates. For Barth and Boyer [10] "the culture in which the consumer is immersed" strongly influences "him through family, educational system, religion and media". This culture is defined as "a set of values, beliefs, symbols, myths, customs and traditions shared by individuals at a given moment and in a given space, concerning modes of behavior and therefore consumption (Data), through the introduction of social norms and codes of conduct". So, when the cultural environment changes, the cultural behavior of the individual are affected". Therefore, "the subculture federates individuals around core values, it has a strong influence on purchasing behavior, including on its periphery, when the styles it generates (hairstyle, clothing, music) is shared or imitated by a wider population". It is then possible to state that culture influences either positively and negatively a customer's loyalty behavior.

In conclusion, three general forms of fidelity that can be adopted:

- Behavioral fidelity that is the repeated purchase of the same brand,

- Attitudinal and affective fidelity that translates the prescription of the brand to other customers and the development of positive word-of-mouth and then

- Normative fidelity which reflects the customer's behavior by respecting the values and norms of the reference culture.

Defining the service VSE: Defining the very small company (VSE) and even the very small craft business is no easy task. Indeed, such a delicacy is blatant insofar as "this category of enterprises has long been ignored not only by policymakers but also by research". And Folliard [11] "this is a situation where everyone knows the reality represented by very small enterprises without being able to define and differentiate it from other forms of organizations. That is why in order to provide some alternative definition, Picard [12] proposes starting from the definition of VSE and identifying it from the main activity (the trade) which is, according to Le Boterf [13], a corpus of knowledge, essentially technical know-how; specific to the community of belonging. This shows that to obtain an appropriate definition, it is necessary to start from the characteristics of the VSE before adding the peculiarity that is the foundation the specific "craft". But the business in question here refers to a mastery of the specific skills to offer a service to customers. Thus, we define artisanal small businesses as " small, legally and financially independent companies, operating in the primary sectors, manufacturing or service sectors, and whose liabilities are most often assumed by a person if not two or three, these being very often the only owners of capital" $[11,14]$. Service VSEs are ones that offers only services. These companies do not produce goods, unlike artisanal smallscale artisanal businesses which are small-scale artisanal businesses located "at the convergence of art and craftsmanship and which refers to the artistic part of the craftsman therefore the service of the 'art' [15].

Considering that "the TPE leader comes from a technical culture which he will profit by creating a company, the latter reflects a certain social mobility and a status, legitimacy otherwise inaccessible" and that it is an "Entrepreneur who lives and works in a geographically limited space. It maintains strong social relations within this space, adheres to the societal values of this space and has business interests mainly within this space" $[11,14,16]$. Therefore, it could be easy to state that customers of these VSEs would develop normative fidelity more than other types of loyalty because of the social environment in which they are.

\section{Methodology}

The main research is as follows: what forms of fidelity do the VSE customers adopt and what relationship exists between the different forms of fidelity adopted. To answer this question, it is assumed that:

Hypothesis $1\left(\mathrm{H}_{1}\right.$ : Clients of artisanal VSE adopt all forms of fidelity.

Hypothesis $2\left(\mathrm{H}_{2}\right)$ : There is a positive correlation between all the forms of fidelity adopted by the VSE customers.

\section{Data collection}

In order to carry out this study successfully, secondary information were collected so as to have a theoretical knowledge of fidelity and the forms of fidelity that can be adopted by the customers on the one hand and to define the VSE on the other hand. The primary data for this study are obtained from a survey carried out on the basis of a questionnaire for small-scale households. The questionnaire developed contains items that are measured with a Likert scale at three levels: "disagree", "indifferent" and "agree". The use of this scale refers to the findings of Sogbossi [17] who indicates that the general confusion on these terms that renders the scales at 5 or 7 points inoperative. Consequently, the use of a three-dimensional scale test, i.e. agree, indifferent and disagree was recommended. This being clarified, the sample is composed of 446 clients selected from three urban communes and three rural communes to whom a questionnaire was administered. However, 419 questionnaires were validated, i.e. a return rate of $93 \%$. The said localities are chosen for pure convenience.

\section{Data analysis}

For questionnaire validation and clarification purpose, EPI DATA 3.1 for Windows 7 was used. The results were exported in SPSS 18 software to calculate correlations and P-value.

The first hypothesis refers to the forms of fidelity adopted by the customers of the artisanal micro-enterprises. Following the literature, three forms of fidelity were identified: normative fidelity, attitudinal and affective fidelity as well as behavioral fidelity. Approximate variables have been created to explain these forms of fidelity. Thus, the normative fidelity is approximated by the variable FINOR, the attitudinal and affective fidelity is approximated by the variable FIATA while the behavioral fidelity is approximated by the variable FICOM. The analysis of the form of fidelity adopted is carried out by means of the mean comparison test (for a single sample). The mean score observed for each type of loyalty adopted is compared with a theoretical average [18]. The theoretical average chosen is two which corresponds to the level of indifference expressed for each component. The comparison test seems to be more appropriate because customer loyalty behavior can be assimilated to a phenomenon following a normal distribution. It can be said that the client adopts a form of fidelity when his average score is greater than the theoretical mean, i.e. a positive deviation from the theoretical average. 
Page 3 of 4

Hypothesis $\mathrm{H}_{2}$ is tested by the evaluation of the coefficient of linear correlation between the variables. If the coefficient is positive, its value is close to 1 and significant at $5 \%$. Then, the types of fidelity adopted evolve in the same direction. Otherwise, the types of fidelity evolve in the opposite direction and the hypothesis $\mathrm{H}_{2}$ is reversed.

\section{Results}

\section{Forms of fidelity adopted by customers}

The form of fidelity adopted depends on the behavior of the customer in the control of the service and his attitude towards others and theirs towards the company. In this study, three types of fidelity were selected. These are behavioral fidelity (FICOM), attitudinal and emotional fidelity (FIATA) and normative fidelity (FINOR). The different average scores obtained for each of the selected variables are summarized in Table 1.

From the analysis of Table 1, it is inferred that only normative fidelity has an average less than two, the theoretical average fixed. This means that customers do not adopt this form of loyalty. On the other hand, they agree on the adoption of the two other types of fidelity with a strong accent. But before drawing a conclusion, it is important to make a test to judge the significance of the different results obtained. This confirmation is made by the test of comparison of mean value with respect to the note 2 (on the single sample).

Of the three types of fidelity, only normative fidelity has a negative $\mathrm{t}$, confirming that customers do not adopt this form of loyalty. In other words, they do not take into account norms and values to be loyal. On the other hand, the other two have a positive $t$ value; which confirms that if customers are loyal, they get the services from the same craftsman and develop positive word-of-mouth or at least talk about the company to other potential customers. An analysis of this Table 2 shows that the two types of fidelity having a positive $t$-value have a $\mathrm{P}$-value of less than 5\%.

\section{Relation between types of loyalty}

In Table 3, correlation test shows that there is a strong correlation between the FICOM and FIATA variables, as 0.451 is close to 1 . As such, clients clearly both type of loyalty together. When the client adopts behavioral fidelity, he adopts a favorable and affective attitude towards the small-scale VSE. And the more he adopts behavioral fidelity, the more he adopts that attitudinal and affective fidelity. Therefore, $\mathrm{H}_{2}$ is confirmed.

\begin{tabular}{|c|c|c|c|c|}
\hline \multicolumn{2}{|c|}{} & FICOM & FIATA & FINOR \\
\hline \multirow{2}{*}{$\mathrm{N}$} & Valid & 419 & 419 & 419 \\
\cline { 2 - 5 } & Missing & 0 & 0 & 0 \\
\hline \multirow{2}{*}{ Std. of the average } & 2.28 & 2.99 & 1.09 \\
\hline \multicolumn{2}{|c|}{ Standard deviation } & 0.030 & 0.007 & 0.019 \\
\hline
\end{tabular}

Sources: Field data, 2014.

Table 1: Mean comparison tes.t

\begin{tabular}{|c|c|c|c|c|c|c|}
\hline & \multicolumn{7}{|c|}{ Test value=2 } \\
\cline { 3 - 8 } & T & DdI & $\begin{array}{c}\text { Sig. } \\
\text { (Bilateral) }\end{array}$ & $\begin{array}{c}\text { Average } \\
\text { difference }\end{array}$ & $\begin{array}{c}\text { Confidence interval 95\% } \\
\text { of difference }\end{array}$ \\
\cline { 6 - 8 } & & & & & Lower & Superior \\
\hline FICOM & 9.486 & 419 & 0.000 & 0.285 & 0.23 & 0.34 \\
\hline FIATA & 139.548 & 419 & 0.000 & 0.987 & 0.97 & 1.00 \\
\hline FINOR & -47.658 & 419 & 0.060 & -0.410 & -0.95 & -0.87 \\
\hline
\end{tabular}

Sources: Field data, 2014.

Table 2: Single sample test.

\begin{tabular}{|c|c|c|c|}
\hline \multicolumn{2}{|c|}{} & FICOM & FIATA \\
\hline \multirow{2}{*}{ Pearson correlation } & FICOM & 1.000 & 0.751 \\
\hline \multirow{2}{*}{ Sig. (Unilateral) } & FIATA & 0.751 & 1.000 \\
\hline & FICOM & - & 0.000 \\
\cline { 2 - 4 } & FIATA & 0.000 & - \\
\hline $\mathbf{N}$ & FICOM & 419 & 419 \\
\hline & FIATA & 419 & 419 \\
\hline
\end{tabular}

Sources: Field data, 2014

Table 3: FICOM*FIATA correlation test.

\section{Conclusion}

This study was set up to determine the different types of fidelity adopted by artisanal VSE and the relationship that could exist between them. The results show that of the three types of fidelity, only two are adopted by customers of craft VSE: behavioral fidelity and attitudinal and affective fidelity. Clients in this industry are not loyal because of standards, values, religion or simply culture. This result confirms that the basis of fidelity in the sector is the satisfaction of the expectations. There is also a correlation between behavioral fidelity and attitudinal and emotional fidelity. Small business owners are then encouraged to use the tools available to meet the expectations of consumers of their services rather than basing themselves on their cultural affiliation with their customers to keep them as long as possible.

Notwithstanding this result, several limitations must be emphasized. The results can only be applied in the context of small-scale service VSE clients. The other reason is the extent of the small-scale VSE customers considered. The fact of choosing only three types of craft enterprise is not sufficiently important for generalization to the other craft enterprises. It would therefore be interesting to introduce artisanal small-scale art which produces artifacts, souvenirs, objects materializing an idea or a membership and to compare the results. Other service sectors, such as religious enterprises, may also be investigated.

\section{References}

1. Pacitto JC, Julien (2006) Is marketing solvable in VSE. International Review of SMEs 19: 78-109.

2. Lacœuilhe J (2000) Attachment to the brand: proposal for a scale of measurement. Research and Applications in Marketing 15: 61-77.

3. Bozzo C, Merunka D, Mills JL (2003) Fidelity and buying behavior: do not rely on appearances. Marketing decisions 1: 9-17.

4. N'goala G (2003) Proposition of a conceptualization and a relational measure of fidelity. Proceedings of the 19th International Congress of the French Marketing Association, pp: 511-531.

5. Trinquecoste JF (1996) Consumer loyalty: a priority marketing objective Marketing decisions 1: 17-23.

6. Olivier R (1997) Satisfaction a behaviour perspective on consumer. McGrawHill, New York.

7. Desormeaux R, Lafrance S (2001) The myth of consumer infidelity. Management 26: 98-103.

8. Jacoby J, Kyner DB (1973) Brand loyalty vs. repeat purchasing behavior. Journal of Marketing Research 1: 1-9.

9. Allen NJ, Meyer JP (1990) The measurement and antecedents of affective, continuance and normative commitment to the organization. Journal of Occupational and Organizational Psychology 63: 1-8.

10. Barth I, Boyer A (2008) The Ethical Challenge of Ethnic Marketing. In: Actes of the International Congress Marketing Trends, Venice.

11. Foliard S (2010) The management of classical VSEs, between territoriality and fidelity. In: CIFEPME 2010 BORDEAUX.

12. Picard C (2006) The identity of artisanal TPE. SME International Journal: Economics and Management of Small and Medium-Sized Enterprises 19: 13-49. 
13. The Boterf G (2000) Building individual and collective skills. Ed. of Organization.

14. Marchesnay M, Julien PA (1990) The small business: as a transaction space. Entrepreneurship \& Regional Development 2: 267-278.

15. Jaouen A, Loup S (2005) Strategic alliance and arts and crafts: Between survival and the quest for legitimacy. AIMS-AIREPME Research Workshop: "Artisanal Small Businesses in the Future", ERFI-Université Montpellier I, pp: 19.
16. Kokou-Dokou G, Gourdon Cabaret D (2006) Relational skills as a source of the success of the recovery of SMEs. Day G. Doriot.

17. Bocco BS (2009) Socio-cultural dimensions of small business enterprise behavior in Africa. Market Management 9: 93-114.

18. Sogbossi BB, Ogouyomi OR (2013) Study of the ethical perception of the leader of the informal enterprise in Benin. 11th International Francophone Congress on Entrepreneurship and SMEs. 